\title{
Panorama Internacional da produção científica sobre Economia Ambiental: Um estudo bibliométrico
}

International panorama of scientific production on Environmental Economics: A bibliometric study

Panorama internacional de la producción científica en Economía Ambiental: Un estudio bibliométrico

\section{Resumo}

A economia ambiental tem por objetivo minimizar o impacto causado no meio ambiente e nos ecossistemas. Para isso, a proposta é maximizar o valor dos recursos por meio da análise detalhada dos efeitos que a exploração ambiental vem causando, como o aquecimento global, o efeito estufa, entre outros impactos negativos. Nesse contexto, o objetivo deste artigo é analisar a produção científica internacional sobre Economia Ambiental, utilizando como base a plataforma Web of Science. Para tanto, como procedimento metodológico, fez-se um estudo bibliométrico, de natureza exploratória e descritiva, em que se mediu a produtividade internacional sobre a temática e se utilizou o software VOSviewer version 1.6.12 para elaborar mapas de formação de clusters, o que possibilitou uma análise relacional entre autores, organizações, países, além de evidenciar a formação de subcampos dentro da temática geral. Os principais resultados apontaram para a evolução da produtividade, principais clusters de autores, organizações e países, além de apontar áreas de pesquisa dentro do campo, a partir do delineamento de grupos de assuntos pesquisados.

Palavras-chave: Economia ambiental; Economia; Produtividade; Bibliometria.

\begin{abstract}
The Environmental Economics has the purpose to minimize the impacts on the environment and the ecosystems. In this regard, the guidance is to maximize the value of the resources by means of a detailed analysis about the effects of the environmental deterioration, such as global warming, greenhouse effect or other negative impacts. In this context, the aim of this article was to analyze the international scientific literature about Environmental Economics indexed in the international database Web of Science. For this purpose, the methodological procedure was the bibliometric survey, using an exploratory and descriptive research, which measures the international productivity on the theme, and used the VOSviewer software version 1.6.12 to develop clusters maps, allowing a relational analysis between authors, organizations, countries, as well as highlighting the elaboration of subfields in the overall thematic. The main results pointed to a productivity development, main authors clusters, organizations and countries, in addition to indicate research areas inside the field, starting from the delimitation of the research subjects.
\end{abstract}

Keywords: Environmental economics; Economy; Productivity; Bibliometrics.

\section{Resumen}

La economía ambiental tiene como objetivo minimizar el impacto sobre el medio ambiente y los ecosistemas. Para ello, la propuesta es maximizar el valor de los recursos a través de un análisis detallado de los efectos que la exploración ambiental viene provocando, como el calentamiento global, el efecto invernadero, entre otros impactos negativos. En este contexto, el objetivo de este artículo es analizar la producción científica internacional en Economía Ambiental, 
tomando como base la plataforma Web of Science. Para ello, como procedimiento metodológico, se realizó un estudio bibliométrico, de carácter exploratorio y descriptivo, en el que se midió la productividad internacional sobre la temática y se utilizó el software VOSviewer versión 1.6.12 para la creación de mapas de formación de clústeres, que posibilitó un análisis relacional entre autores, organizaciones, países, además de evidenciar la formación de subcampos dentro del tema general. Los principales resultados apuntaron a la evolución de la productividad, principales clusters de autores, organizaciones y países, además de señalar áreas de investigación dentro del campo, a partir del esquema de grupos de temas investigados.

Palabras clave: Economía ambiental; Economía; Productividad; Bibliometría.

\section{Introdução}

As origens da Economia Ambiental encontram-se no ano de 1950 quando, nos Estados Unidos, a Resources for the Future (RFF) foi estabelecida em Washington. A RFF é uma organização de pesquisa independente que desenvolveu o conceito e a aplicação da economia atrelada a uma grande variedade de questões ambientais. No final da década de 1960 a Economia Ambiental atingiu a maioridade. O pano de fundo para o seu desenvolvimento foi a revolução ambiental iniciada por Rachel Carson, em sua obra Silent Spring lançada no ano de 1962. Para Cropper e Oates (2008), as advertências de Carson sobre os efeitos nocivos provocados pelo uso dos agroquímicos não eram novidade e a perspectiva de que a economia teria um certo grau de participação nas preocupações apontadas por Carson não era surpreendente. Os agroquímicos apontados como os grandes vilões eram e são grandes negócios, assim como o uso de produtos químicos como o DDT na agricultura contribui para o aumento da produtividade agrícola e a garantia de uma quantidade suficiente de recursos em resposta a demanda por alimentos.

Segundo Pearce (2002), os economistas já estavam familiarizados com a ideia de que provavelmente haveriam custos e benefícios de qualquer atividade econômica, sendo que estes custos assumiriam a forma de "efeitos externos", neste caso, a perda de biodiversidade, acentuando o grau de preocupação por partes das pessoas como nunca havia acontecido. Dessa forma, os economistas começaram a vincular a teoria dos efeitos externos com uma interpretação econômica dos efeitos e impactos ambientais crescentes em todo o mundo.

Pearce (2002), levanta a ideia de que desenvolvimento sustentável tornou-se um objetivo central na política econômica moderna. Sua concepção mais célebre vem da Comissão Mundial sobre Meio Ambiente e Desenvolvimento (a Comissão Brundtland) onde apresenta o Desenvolvimento sustentável como aquele que atende às necessidades do presente sem comprometer a capacidade das gerações futuras de encontrar os seus próprios necessidades. Ele levanta dois conceitos chave, em termos econômicos, a definição envolve a noção de um sistema econômico em cujo bem-estar per capita aumenta com o tempo de forma sustentada. Ideia semelhante, mesmo sendo uma posição menos pesquisada, se aplicaria à distribuição atual de bem-estar. Mas modelos de crescimento econômico tradicionalmente adotaram a mesma perspectiva observando os caminhos de crescimento de utilidade e consumo. Portanto, para Pearce (2002), parece apropriado e necessário reinterpretar a teoria tradicional do crescimento em termos de desenvolvimento sustentável.

Welsch (2009), afirma que até o passado recente, a Economia Ambiental foi severamente restringida pela não observância de alguns de seus conceitos mais fundamentais, preferências e utilidades. Semelhante a outros campos da economia, esta limitação obrigou os pesquisadores a basear suas análises em um conjunto de suposições ou hipóteses mantidas que são não acessíveis a testes empíricos. Segundo Welsch (2009), alguns dos aspectos fundamentais as suposições geralmente aplicadas em análises econômicas ambientais são em sua avaliação de utilidade de bens de mercado e bens ambientais, ao decidir sobre o comportamento ambientalmente relevante, as pessoas fazem escolhas individualmente otimizadas para maximizar a utilidade e, sob a presunção de comportamento de maximização da utilidade, as pessoas a valorização dos bens ambientais é revelada por suas escolhas sobre bens de mercado. Dessa forma, faz-se necessário analisar a Economia Ambiental sob os vários contextos sociais, ambientais e econômicos onde estão inseridos, sendo necessário um conhecimento mais aprofundado sobre o que se pesquisa dentro da temática. 
Apesar dos avanços em pesquisas e proposituras destacados sobre o tema, parece adequado compreender o campo de estudo, buscando esclarecer marcos teóricos, assim como áreas de estudo, lacunas de pesquisa ou subcampos em desenvolvimento. Neste sentido, busca-se dar amparo conceitual para a construção de novos paradigmas teóricos acerca da temática abordada.

Diante desse contexto, este artigo tem como objetivo analisar a produção científica internacional sobre Economia Ambiental, buscando a compreensão das principais características das publicações científicas, como os principais clusters de coautoria entre autores, países e organizações, assim como os termos em evidência nas publicações sobre a temática, com a geração de redes bibliométricas por meio do software VOSviewer. Partiu-se da premissa de que a presente pesquisa se justifica pela relevância em disponibilizar uma visão abrangente do panorama atual da pesquisa sobre a Economia Ambiental.

\section{Os paradigmas da Economia Ambiental}

$\mathrm{O}$ crescimento da população mundial e o rápido crescimento da atividade econômica tem causado estresse ambiental em todos os sistemas socioeconômicos. Existe um amplo consenso científico de que problemas como o efeito estufa (e alterações climáticas), destruição da camada de ozônio, chuva ácida, perda de biodiversidade, poluição tóxica e o esgotamento de recursos renováveis e não renováveis são sintomas claros de insustentabilidade ambiental (MUNDA, 1997). O surgimento de diferentes tipos de crises sociais, ambientais e econômicas, derivadas da ação do homem e da forma de organização econômica atual, provocaram a Ciência econômica a definir o seu papel diante dos problemas ambientais, incorporando, desta forma, a necessidade de avaliar e definir parâmetros racionais de análise.

As externalidades estão no centro da economia ambiental, segundo Greenstone e Gayer (2009), o grande problema é que as empresas não internalizam os custos de saúde que impõem a terceiros por meio da liberação da poluição do ar. Altos custos de transação frequentemente impedem as partes afetadas de alcançar uma solução eficiente que contabiliza os custos e benefícios, neste caso o papel intervencionista dos governos por meio de impostos ou limite de emissões devem ser utilizados como mecanismos de redução dos impactos. O foco principal da economia ambiental é abordar as ineficiências causadas por externalidades. A utilidade de qualquer uma das prescrições de políticas decorrentes desta abordagem se baseiam diretamente na confiabilidade das estimativas empíricas dos benefícios e custos de redução da poluição, portanto é importante compreender a validade das diferentes abordagens empíricas para estimar as relações causais entre a atividade econômica e as externalidades (LINARES, 2002).

Como todas as subdisciplinas da economia, a economia ambiental emprestou muito do pensamento de seus precursores. A ideia de uma externalidade, um efeito prejudicial (ou benéfico) para um terceiro, para o qual nenhum preço é cobrado, já era familiar da obra de Pigou na década de 1920 (ANDERSEN, 2007). Nesta perspectiva, ainda segundo o autor, a noção de valor do meio ambiente foi incorporada, visualizando as funções do meio ambiente dentro do contexto econômico.

$\mathrm{O}$ ambiente claramente possui valores em seus próprios direitos, e a análise econômica ambiental antropocêntrica considera a abordagem aplicada, com ênfase na utilidade do ambiente para humanos, medido em termos de bem-estar econômico. Shogren e Taylor (2008), afirmam que o meio ambiente pode ser reconhecido como cumprindo quatro condições econômicas básicas de bem-estar, sendo, valores de amenidade; uma base de recursos para a economia; um sumidouro para fluxos residuais; um sistema de suporte de vida. Shogren e Taylor (2008) apresentam essas quatro funções e suas interligações dentro do contexto de "economia circular", esta economia do ponto de vista da economia ambiental é baseada em um equilíbrio de materiais, o que implica que todos fluxos de materiais precisam ser contabilizados, embora serão os valores econômicos, não os fluxos físicos, que orientam a sua gestão. 
Segundo Munda (1997), a economia ambiental pode ser considerada como uma especialização particular de economia neoclássica estudando duas questões fundamentais: o problema das externalidades ambientais; e a gestão correta dos recursos naturais (em particular, a alocação ótima entre as gerações de recursos não renováveis).

Os profissionais da economia ambiental desenvolvem informações teóricas e modelos práticos a partir da possibilidade de escassez. Dessa forma, são estimados valores para criar indicadores de prioridade, que servem como base para outras especialidades. Enquanto a economia ecológica, por sua vez, visa o bem-estar humano por meio do seu desenvolvimento, que deve ser executado de acordo com um planejamento sustentável para todo meio ambiente e a sociedade. Ela incorpora a economia tradicional, mas envolve também a relação entre as pessoas e empresas com o meio ambiente. A economia ecológica mede os limites de utilização da natureza e do descarte de resíduos no seu ecossistema, compreendendo que os mesmos materiais colhidos na natureza são descartados de forma equivocada, ilegal e até criminosa (FISHER, 2000).

A economia ambiental recebe influência direta da Economia comportamental, que, segundo Shogren e Taylor (2008), teve provavelmente o maior impacto na Economia Ambiental, por meio da aplicação de pesquisas sobre a avaliação fora do mercado de bens ambientais. Os economistas ambientais documentaram desvios empíricos entre a teoria e o comportamento, eliminando a ideia de que a escolha racional e a economia do bem estar devem permanecer como base analítica incontestada para a avaliação ambiental. Além disso, para Pindyck (2002), na economia ambiental, existem dois tipos de incerteza, a primeira é a incerteza sobre os custos e benefícios futuros dos danos ambientais e sua redução. No caso do aquecimento global, mesmo que se soubesse o quão grande é o aumento de temperatura esperado, não se saberia o custo resultante para a sociedade, não se poderia, por exemplo, prever como um aumento de temperatura afetaria a produção agrícola. A segunda é a incerteza ecológica, ou seja, a incerteza sobre a evolução dos ecossistemas relevantes. Por exemplo, mesmo se soubéssemos que poderíamos cumprir uma meta de política específica para as emissões de carbono nos próximos 40 anos, não saberíamos o resultado dos níveis de concentrações atmosféricas de carbono.

Uma outra variável levantada pela Economia Ambiental é a relação custo benefício e a integração dos impactos ambientais na análise. Para Pearce (2002), por meio das técnicas de medição do valor econômico de mudanças nos ativos ambientais, a análise de custo-benefício tornou-se mais completa em sua cobertura. Dado que o custo-benefício sempre alegou medir todas as mudanças no bem-estar com um projeto ou política, e com base nesse princípio, todos os projetos e políticas têm impactos ambientais, e a possibilidade deste processo de estender a análise de custo-benefício era importante.

É possível concluir que os estudos sobre Economia Ambiental são necessários e que as bases conceituais assim como a sua aplicabilidade devem ser reconhecidos pelos vários tipos de ciências, esta Economia, considerada parte de um campo amplo das Ciências ambientais, permite, segundo van den Bergh (2007), compreender melhor as causas dos problemas ambientais, bem como as características e limites para soluções dos problemas ambientais.

\section{Metodologia}

Considerando que buscou mapear a estrutura do campo de conhecimento mencionado anteriormente, por meio de dados, e que, além disso, teve o intento de investigar a evolução do tema em foco, via avaliação de performance de pesquisadores e autores, este estudo possui uma natureza bibliométrica (KOSEOGLU, 2016). Dessa maneira, fez-se uso de técnicas avaliativas - em que foram observadas medidas de produtividade e métricas de impacto - e relacionais, através de construção de mapas e redes de coautoria e ocorrência. Ainda por proporcionar uma perspectiva geral sobre o objeto em estudo (do tipo aproximativo) e por procurar descrever as características deste mesmo objeto, a pesquisa se caracteriza como exploratória e descritiva (GIL, 2008). 
Por sua vez, o procedimento de pesquisa consistiu nas etapas descritas a seguir. O ponto de partida foi a escolha do tema: Economia Ambiental. Esta foi uma temática cuja abordagem destacou-se na disciplina Economia e Meio Ambiente, cursada pelos autores no Doutorado em Engenharia e Gestão de Recursos Naturais, da Universidade Federal de Campina Grande (UFCG).

A segunda etapa foi o levantamento inicial das publicações, cujo procedimento descrito a seguir foi realizado em $11 \mathrm{de}$ setembro de 2020. Como base, utilizou-se a plataforma Web of Science (v. 5.35), utilizando-se os índices de pesquisa (coleções) Science Citation Index Expanded (SCI-EXPANDED), Social Sciences Citation Index (SSCI) e Emerging Sources Citation Index (ESCI) - esta escolha ocorreu em função do perfil das publicações em consonância com as áreas representadas por cada uma das coleções selecionadas. Procurou-se publicações que contivessem em seus títulos "environmental economics" ou "environmental economy". Optou-se pela busca apenas em títulos (e não em títulos, resumos e palavras-chave) para evitar que trabalhos não relacionados com a temática fossem incluídos por indexação equivocada ou coincidência de menção em resumo. Foram incluídos na pesquisa todos os anos disponíveis na base (1945 a 2020), de maneira a ampliar o máximo possível o escopo do estudo. Essa abordagem inicial, resultou em um total de 329 publicações identificadas. Por fim, ainda foi realizado um refinamento: mantiveram-se na amostra apenas as publicações do tipo article e review. Dessa forma, o total de publicações selecionadas foi de 147. O script final da busca foi: "Banco de dados: Principal Coleção do Web of Science TíTULO: ("Environmental economics" or "environmental economy") Refinado por: DOCUMENT TYPES: (ARTICLE OR REVIEW) AND [excluding]: DOCUMENT TYPES: (EARLY ACCESS) AND DOCUMENT TYPES: (ARTICLE OR REVIEW)".

A terceira etapa consistiu no tratamento dos dados. Inicialmente, ainda na plataforma Web of Science, utilizou-se a ferramenta Clarivate Analytics e, a partir desta, foram gerados gráficos de frequência abordando publicações por: áreas, anos, periódicos, organizações e países. Em seguida, fez-se o download tabulado dos dados consolidados na segunda etapa e elaborouse ranking, com base em quantidade de citações recebidas, e classificou-se as publicações de acordo com seu Fator H (H-Index), resultando em um panorama geral sobre relevância e impacto das publicações no campo em estudo. Nesse sentido, um pesquisador possui Fator $\mathrm{H}$ se seu $N p$ (número de publicações) tiver um mínimo de $h$ citações, cada um deles, e, os demais estudos, tiverem menos ou iguais citações cada um (HIRSCH, 2005). Por fim, fez-se uso do software VOSviewer version 1.6.12. O VOSviewer é um programa que oferece ferramentas para construção e visualização de redes bibliométricas (VAN ECK et al., 2017). A partir deste, foram formuladas redes bibliométricas com base nos tipos e unidades de análise listados no Quadro 1.

Quadro 1 - Definição dos parâmetros de corte no VOSviewer.

\begin{tabular}{|l|l|l|}
\hline \multicolumn{2}{|c|}{ PARÂMETROS } & \multicolumn{1}{c}{ DESCRIÇÃo } \\
\cline { 1 - 2 } Tipo de Análise & Unidade de Análise & \\
\hline Co-authorship & Authors & $\begin{array}{l}\text { Relação de força que ocorre quando, em síntese, autores participam } \\
\text { de publicações em parceria. }\end{array}$ \\
\hline Co-authorship & Organizations & $\begin{array}{l}\text { Relação de força que ocorre quando, em síntese, organizações } \\
\text { participam de publicações em parceria. }\end{array}$ \\
\hline
\end{tabular}




\begin{tabular}{|l|l|l|}
\hline Co-authorship & Countries & $\begin{array}{l}\text { Relação de força que ocorre quando, em síntese, países participam } \\
\text { de publicações em parceria. }\end{array}$ \\
\hline Co-occurrence & All Keywords & Relação de força e frequência entre palavras-chave (termos). \\
\hline
\end{tabular}

Fonte: Adaptado de Van Eck et al. (2017).

A partir das redes bibliométricas construídas, observou-se, com ênfase, a formação de clusters para cada um dos parâmetros elencados no quadro 1. Tal escolha se deu visto que as técnicas de clusterização se apresentam como instrumentos proeminentes no campo da pesquisa bibliométrica, sendo utilizados para identificar grupos de relacionamento entre publicações, autores ou fontes de publicação (VAN ECK et al., 2017).

Por fim, em termos de procedimento, a partir dos resultados gráficos obtidos na etapa, fez-se uma interpretação objetiva dos mesmos, a partir das técnicas avaliativas e relacionais aplicadas, procurando dar destaque aos aspectos mais relevantes em termos de métricas e associação.

\section{Resultados e Discussão}

As primeiras publicações sobre a temática Economia Ambiental aconteceram em 1970. Trata-se de Pesticide Residues And Environmental Economics, de W. F. Edwards, M. R. Langham e J. C. Headley e de Environmental Economics, de T. D. Crocker e A. J. Rogers, publicados, respectivamente, em Natural Resources Journal e Forensic Quarterly. A partir destas, o volume de publicações por se deu conforme apresenta a figura 1, a seguir.

Figura 1 - Quantidade de publicações por ano.

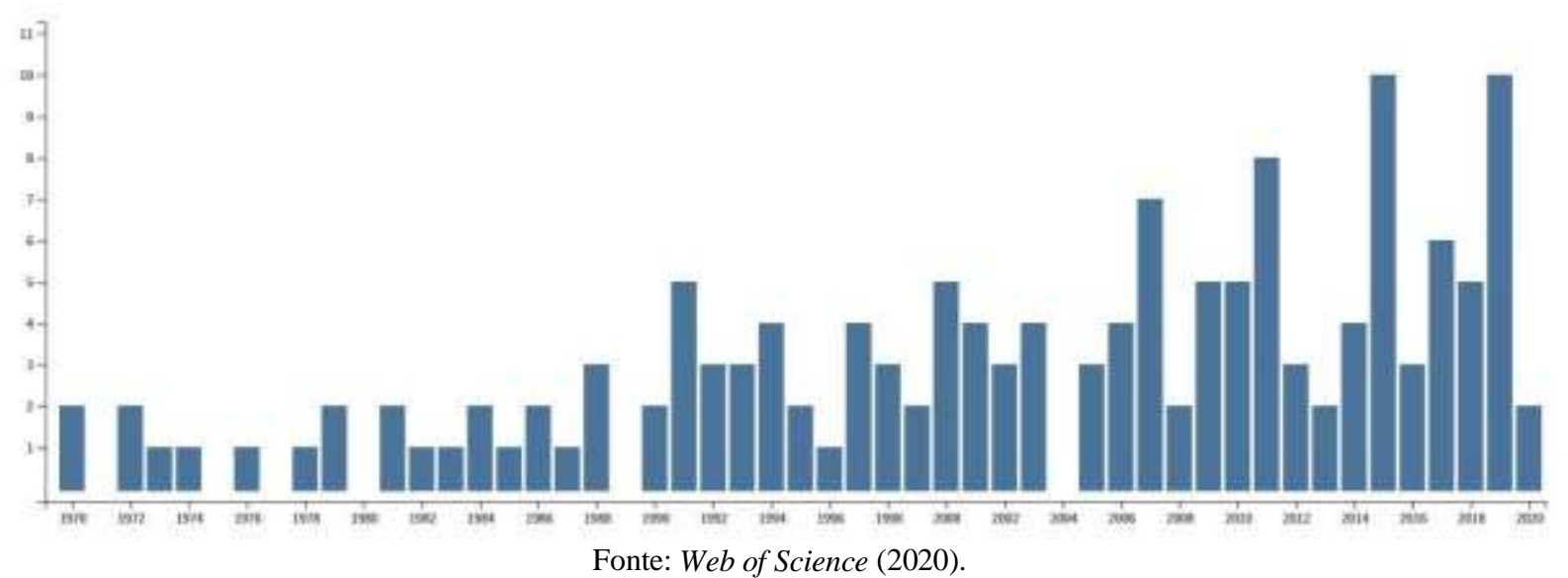

Conforme se observa, o nível de publicações se mantém em seu padrão inicial até o início dos anos 1990, quando converge para uma tendência de crescimento. Tal tendência, porém, não se concretiza em um crescente anual, pois o fluxo de publicações apresenta bastante variabilidade ano após ano. Todavia, a partir de 2007 o volume de publicações sobre a temática acentua o crescimento até atingir sem pico em 2015 e 2019 com 10 publicações em cada ano. Por outro lado, é possível investigar o interesse sobre o tema averiguando a quantidade de referências feitas a esses trabalhos ao longo do tempo, ou seja, a quantidade de citações que recebem. A evolução dessa variável é observada na Figura 2, a seguir. 
Figura 2 - Quantidade de citações por ano

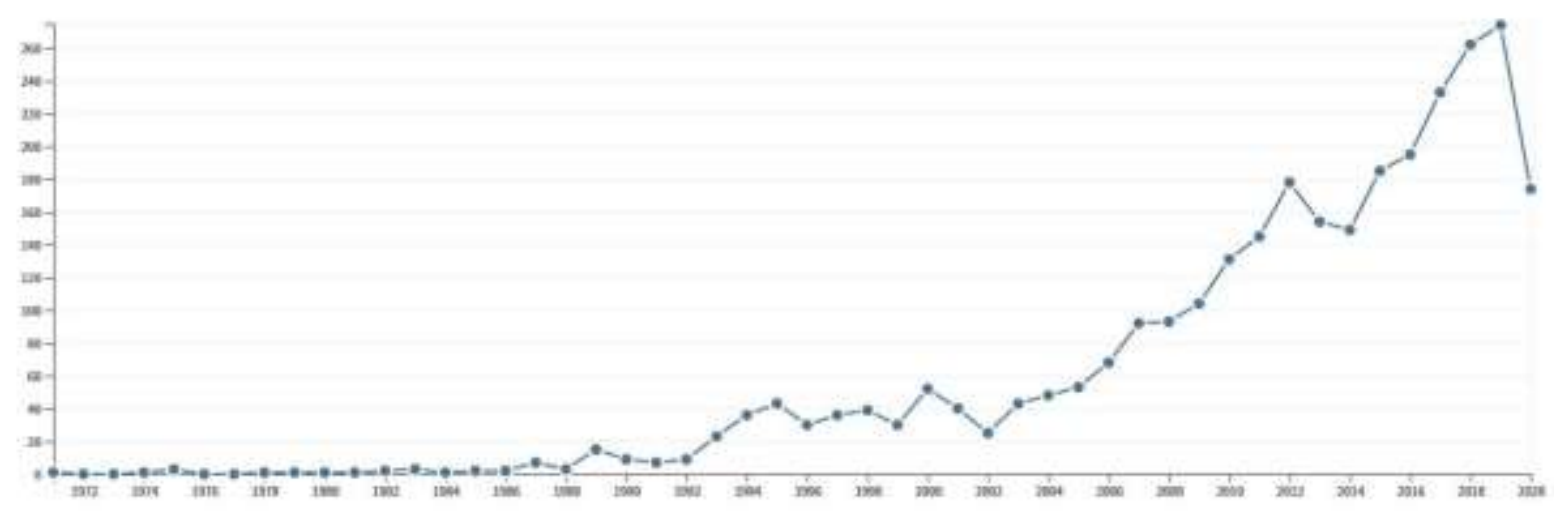

Fonte: Web of Science (2020).

De acordo com os resultados obtidos, fica claro que a partir dos anos 90 e, principalmente, anos 2000 as publicações sobre a temática vêm despertando mais interesse, atingindo seu patamar mais elevado (e atual), a partir dos anos 2010. Além da relevância natural que a temática recebeu no século atual, a disseminação do acesso às tecnologias da informação e, por consequência, aos estudos aqui objeto de pesquisa pode ter relação com o aumento de menções e referências. Passando para o perfil das publicações em estudo, observa-se na Figura 3, a seguir, quais as áreas de pesquisa com maior frequência de publicação.

Figura 3 - Quantidade de publicações por área.

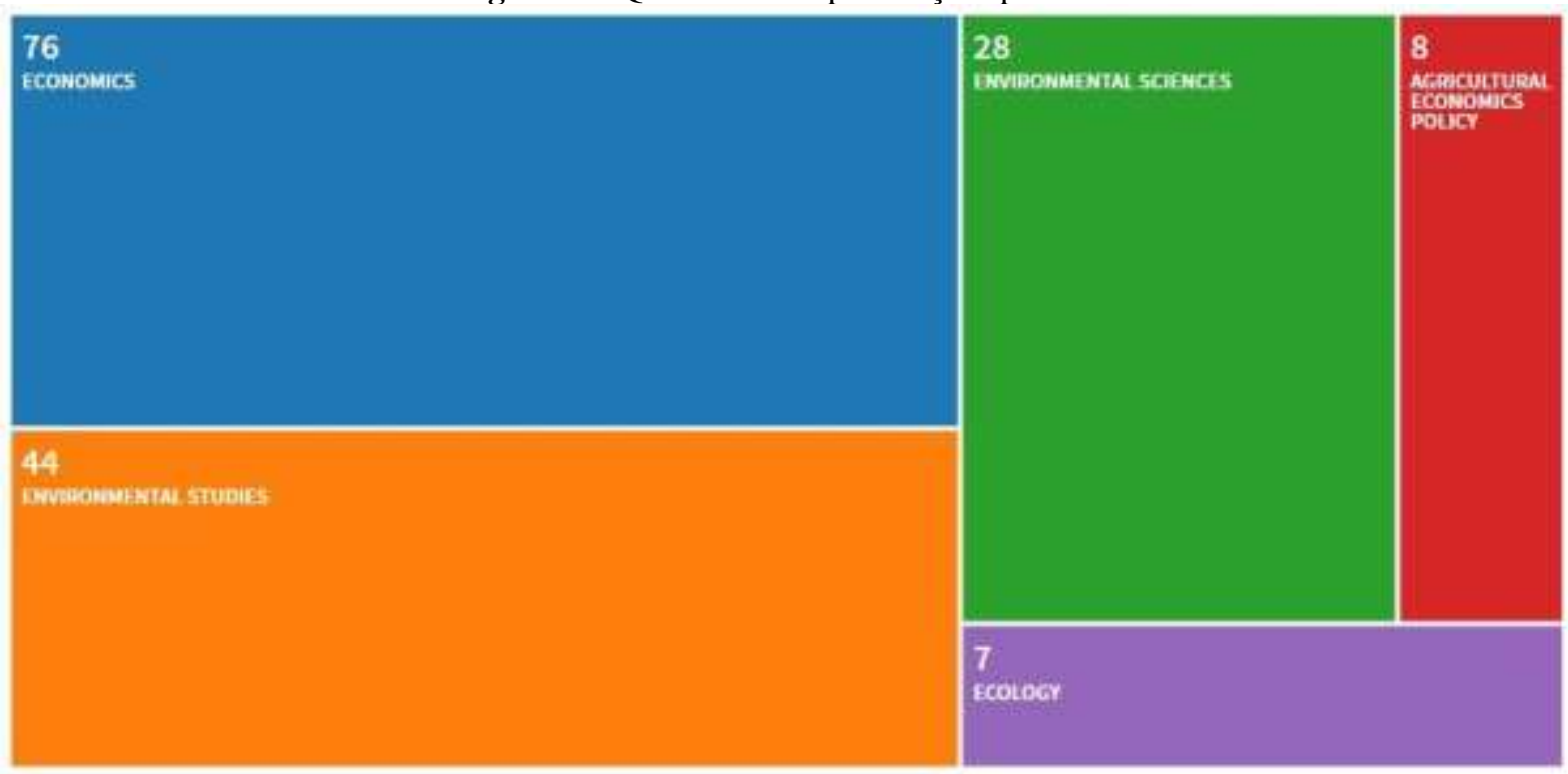

Fonte: Web of Science (2020).

$\mathrm{Na}$ figura em questão estão apresentadas as cinco grandes áreas com mais publicações sobre Economia Ambiental. Conforme esperado, a área de Economia detém a maioria das publicações: 76 (pouco mais da metade do total de trabalhos publicados). Em seguida, tem-se a área de Estudos Ambientais com 44 publicações. Apenas essas duas áreas são responsáveis por $82 \%$ do total de publicações. Os $18 \%$ restante encontram-se fragmentados em ciências de diversas áreas. Parece importante destacar que algumas publicações estão classificadas em mais de uma área de estudo. A constatação sobre áreas de publicação remete diretamente às instituições que estão vinculadas aos pesquisadores. Na Figura 4, a seguir, é possível constatar a quantidade de publicações por instituição. 
Figura 4 - Quantidade de publicações por instituição.

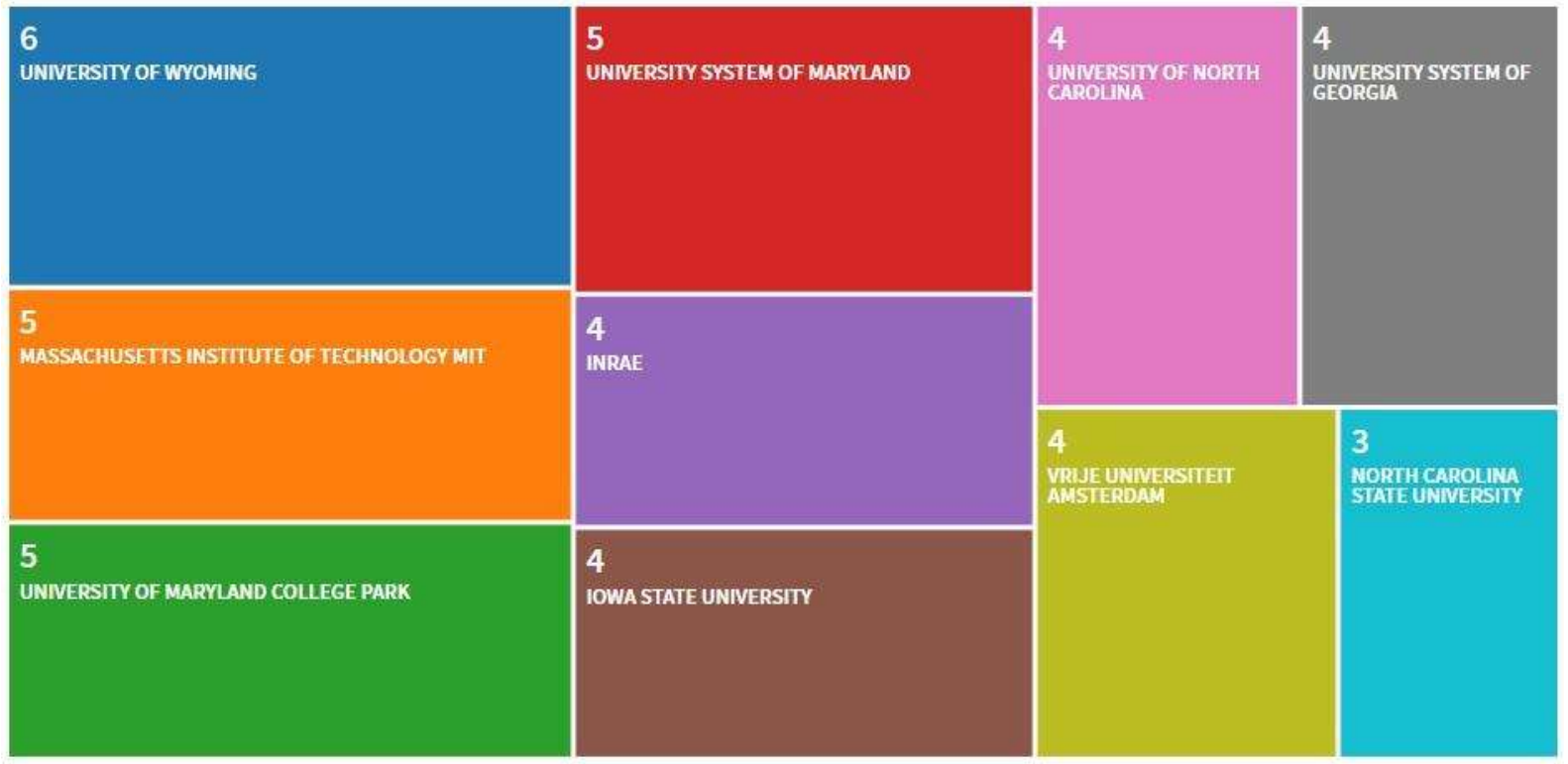

Fonte: Web of Science (2020).

Diferentemente das publicações por área, não existe uma preponderância significativa de publicações por organizações em relação à temática em estudo. Aqui se observa uma massiva fragmentação. Por uma margem mínima, a University of Wyoming é a detentora da maior quantidade de publicações (6), todavia esse volume representa apenas 4\% do total. Ao todo, 173 organizações possuem pesquisadores que publicaram trabalhos relacionados ao campo de Economia Ambiental. Ainda assim, é interessante observar uma maioria significativa de organizações americanas trabalhando a temática - percepção que será reforçada mais adiante. Neste ponto, cabe verificar quais periódicos são referência sobre publicações em Economia Ambiental. Os dados a respeito estão apresentados na Figura 5, a seguir.

Figura 5 - Quantidade de publicações por periódico.

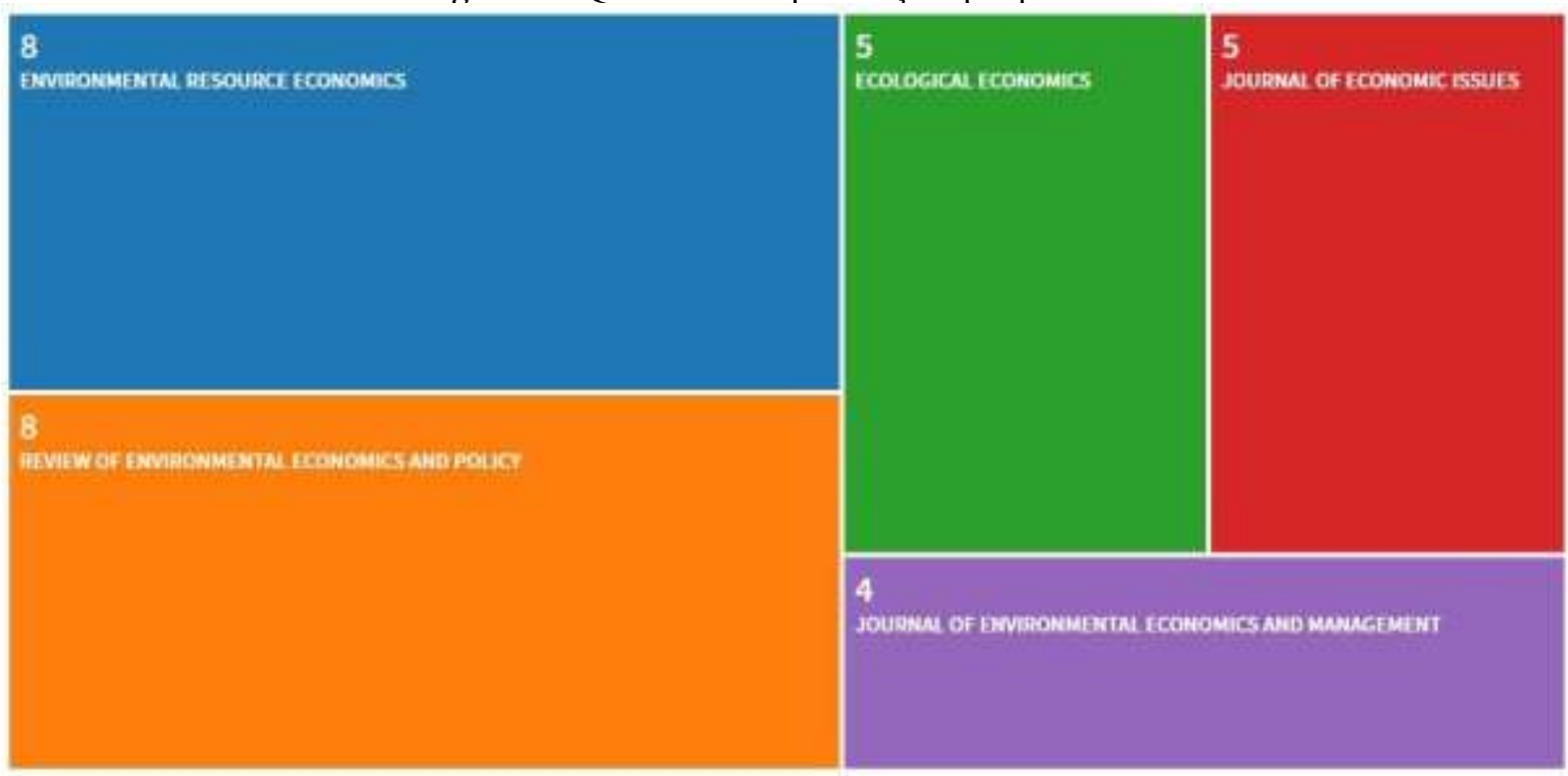

Fonte: Web of Science (2020). 
Assim como nas publicações por organizações, ao se analisar as publicações por periódicos nitidamente se observa um espalhamento natural de pesquisas por uma quantidade elevada de revistas. As revistas mais destacadas são Environmental Resource Economics e Review Environmental Economics and Policy, cujas publicações representam 11\% do total. A partir daí, tem-se um grande volume de periódicos que publicaram pesquisas sobre Economia Ambiental, porém com uma frequência reduzida. Ao todo, são 98 periódicos com publicações identificadas. Por fim, para avaliar de forma geral o perfil das publicações, fez-se necessário investigar a nacionalidade dos autores que pesquisaram e publicaram sobre o tema. Os resultados consolidados são apresentados na Figura 6, a seguir.

Figura 6 - Quantidade de publicações por países.

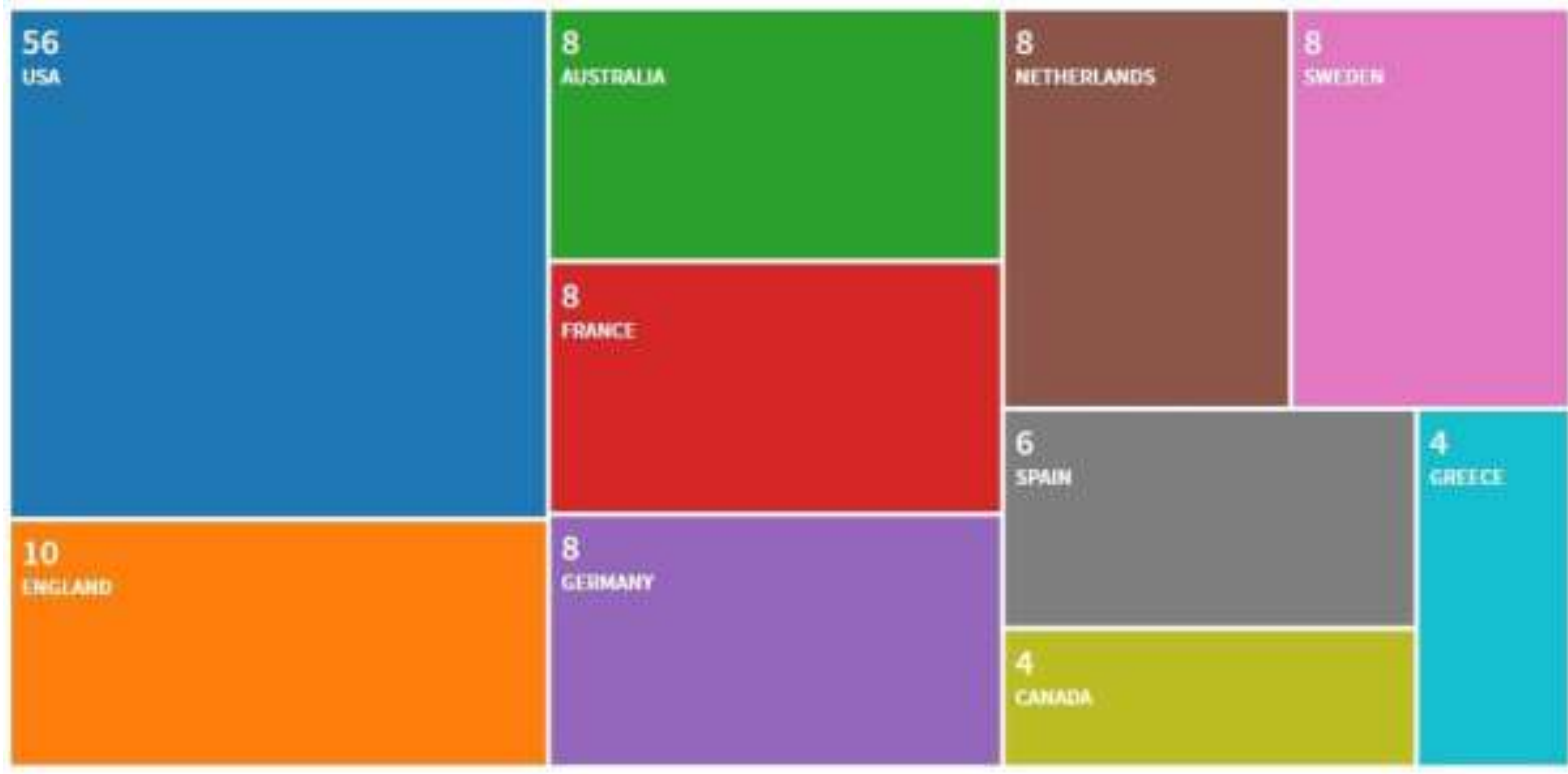

Fonte: Web of Science (2020).

A maior quantidade de publicações tem origem nos EUA. As publicações de pesquisadores estadunidenses correspondem a aproximadamente 38\% do total. Nota-se o que é possível interpretar como um "domínio" sobre o campo por parte desse país, visto que o segundo com mais publicações (Inglaterra) aparece com apenas 7\% do total. Já em termos continentais, observa-se grande presença europeia entre os 10 países com mais publicações: 70\%. Em termos de América Latina, percebe-se uma produtividade incipiente sobre a temática: apenas Brasil, Chile e Equador publicaram pesquisas nesse campo (uma publicação cada um), correspondendo a apenas $2 \%$ do total de pesquisas publicadas.

Passando para a análise específica das publicações, utilizou-se o Fator H (H-Index) para concluir sobre o impacto das pesquisas participantes da amostra deste estudo. Através da aplicação do Fator H obteve-se o resultado exposto no Quadro 2, a seguir.

Quadro 2 - Publicações de maior impacto, de acordo com o Fator H (H-Index).

\begin{tabular}{|l|l|l|l|l|}
\hline Publicação & Primeiro Autor & Título da Fonte & Ano & Citações \\
\hline Environmental economics - a survey & Cropper, M. L. & $\begin{array}{l}\text { Journal of economic } \\
\text { literature }\end{array}$ & 1992 & 554 \\
\hline $\begin{array}{l}\text { An introductory note on the } \\
\text { environmental economics of the circular } \\
\text { economy }\end{array}$ & $\begin{array}{l}\text { Andersen, Mikael } \\
\text { Skou }\end{array}$ & Sustainability science & 2007 & 202 \\
\hline $\begin{array}{l}\text { On Behavioral-Environmental } \\
\text { Economics }\end{array}$ & Shogren, Jason F. & $\begin{array}{l}\text { Review of environmental } \\
\text { economics and policy }\end{array}$ & 2008 & 126 \\
\hline
\end{tabular}




\begin{tabular}{|c|c|c|c|c|}
\hline $\begin{array}{l}\text { Uncertainty in Environmental } \\
\text { Economics }\end{array}$ & Pindyck, Robert S. & $\begin{array}{l}\text { Review of environmental } \\
\text { economics and policy }\end{array}$ & 2007 & 118 \\
\hline $\begin{array}{l}\text { Optimal timing problems in } \\
\text { environmental economics }\end{array}$ & Pindyck, R. S. & $\begin{array}{l}\text { Journal of economic } \\
\text { dynamics \& control }\end{array}$ & 2002 & 109 \\
\hline $\begin{array}{l}\text { Quasi-experimental and experimental } \\
\text { approaches to environmental economics }\end{array}$ & $\begin{array}{l}\text { Greenstone, } \\
\text { Michael }\end{array}$ & $\begin{array}{l}\text { Journal of environmental } \\
\text { economics and } \\
\text { management }\end{array}$ & 2009 & 108 \\
\hline $\begin{array}{l}\text { An intellectual history of environmental } \\
\text { economics }\end{array}$ & Pearce, D. & $\begin{array}{l}\text { Annual review of energy } \\
\text { and the environment }\end{array}$ & 2002 & 96 \\
\hline $\begin{array}{l}\text { Estimating the monetary value of health } \\
\text { care: lessons from environmental } \\
\text { economics }\end{array}$ & Hanley, N. & Health economics & 2003 & 89 \\
\hline $\begin{array}{l}\text { Environmental economics, ecological } \\
\text { economics, and the concept of } \\
\text { sustainable development }\end{array}$ & Munda, G. & Environmental values & 1997 & 83 \\
\hline $\begin{array}{l}\text { Environmental economics and the } \\
\text { Murray-Darling river system }\end{array}$ & Quiggin, J. & $\begin{array}{l}\text { Australian journal of } \\
\text { agricultural and } \\
\text { resource economics }\end{array}$ & 2001 & 73 \\
\hline $\begin{array}{l}\text { Models in evolutionary economics and } \\
\text { environmental policy: Towards an } \\
\text { evolutionary environmental economics }\end{array}$ & Faber, Albert & $\begin{array}{l}\text { Technological } \\
\text { forecasting and social } \\
\text { change }\end{array}$ & 2009 & 72 \\
\hline $\begin{array}{l}\text { Evolutionary thinking in environmental } \\
\text { economics }\end{array}$ & $\begin{array}{l}\text { van den Bergh, } \\
\text { Jeroen C. J. M. }\end{array}$ & $\begin{array}{l}\text { Journal of evolutionary } \\
\text { economics }\end{array}$ & 2007 & 66 \\
\hline $\begin{array}{l}\text { Aggregation of preferences in an } \\
\text { environmental economics context: a } \\
\text { goal-programming approach }\end{array}$ & Linares, P. & $\begin{array}{l}\text { Omega-international } \\
\text { journal of management } \\
\text { Science }\end{array}$ & 2002 & 63 \\
\hline $\begin{array}{l}\text { Investment under uncertainty and option } \\
\text { value in environmental economics }\end{array}$ & Fisher, A. C. & $\begin{array}{l}\text { Resource and energy } \\
\text { economics }\end{array}$ & 2000 & 57 \\
\hline $\begin{array}{l}\text { Environmental economics - an } \\
\text { evolutionary critique and a plea for } \\
\text { pluralismo }\end{array}$ & Norgaard, R. B. & $\begin{array}{l}\text { Journal of environmental } \\
\text { economics and } \\
\text { management }\end{array}$ & 1985 & 57 \\
\hline $\begin{array}{l}\text { Elements of a neoinstitutional } \\
\text { environmental economics }\end{array}$ & Swaney, J. A. & $\begin{array}{l}\text { Journal of economic } \\
\text { issues }\end{array}$ & 1987 & 55 \\
\hline $\begin{array}{l}\text { Behavioral Environmental Economics: } \\
\text { Promises and Challenges }\end{array}$ & Croson, Rachel & $\begin{array}{l}\text { Environmental \& } \\
\text { resource economics }\end{array}$ & 2014 & 53 \\
\hline $\begin{array}{l}\text { Implications of happiness research for } \\
\text { environmental economics }\end{array}$ & Welsch, Heinz & Ecological economics & 2009 & 53 \\
\hline $\begin{array}{l}\text { Fair Air: Distributive Justice and } \\
\text { Environmental Economics }\end{array}$ & $\begin{array}{l}\text { Johansson- } \\
\text { Stenman, Olof }\end{array}$ & $\begin{array}{l}\text { Environmental \& } \\
\text { resource economics }\end{array}$ & 2010 & 51 \\
\hline $\begin{array}{l}\text { Ecological economics: themes, } \\
\text { approaches, and differences with } \\
\text { environmental economics }\end{array}$ & $\begin{array}{l}\text { van den Bergh, } \\
\text { Jeroen C. J. M. }\end{array}$ & $\begin{array}{l}\text { Regional environmental } \\
\text { change }\end{array}$ & 2001 & 50 \\
\hline $\begin{array}{l}\text { Environmental economics of coral reef } \\
\text { destruction in Sri }\end{array}$ & Berg, H. & Ambio & 1998 & 45 \\
\hline $\begin{array}{l}\text { Some problems with environmental } \\
\text { economics }\end{array}$ & Sagoff, M. & Environmental ethics & 1988 & 40 \\
\hline $\begin{array}{l}\text { Experiments in environmental economics } \\
\text { and some close relatives }\end{array}$ & Sturm, Bodo & $\begin{array}{l}\text { Journal of economic } \\
\text { surveys }\end{array}$ & 2006 & 38 \\
\hline $\begin{array}{l}\text { A reexamination of the role of } \\
\text { thermodynamics for environmental } \\
\text { economics }\end{array}$ & Sollner, F. & Ecological economics & 1997 & 37 \\
\hline $\begin{array}{l}\text { Property rules, liability rules, and } \\
\text { environmental economics }\end{array}$ & Bromley, D. W. & $\begin{array}{l}\text { Journal of economic } \\
\text { issues }\end{array}$ & 1978 & 37 \\
\hline $\begin{array}{l}\text { The importance of ethics in } \\
\text { environmental economics with a focus on } \\
\text { existence values }\end{array}$ & $\begin{array}{l}\text { Johansson- } \\
\text { Stenman, O. }\end{array}$ & $\begin{array}{l}\text { Environmental \& } \\
\text { resource economics }\end{array}$ & 1998 & 35 \\
\hline $\begin{array}{l}\text { Environmental economics and ecological } \\
\text { economics: Where they can converge? }\end{array}$ & Venkatachalam, L. & Ecological economics & 2007 & 29 \\
\hline
\end{tabular}


Conforme observado, o H-Index da temática em estudo foi 27 - o que resultou nas 27 publicações listadas no quadro, de acordo com sua relevância e nível de impacto metrificado em número de citações recebidas. A obra de maior impacto sobre Economia Ambiental é Environmental economics - a survey, escrita por M. L. Cropper e W. E. Oates. Foi publicada em 1992 no Journal of economic literature e já foi citada por mais de 550 outras publicações. Mais da metade (59\%) das publicações de maior impacto na temática foram publicadas na década de 2000. Apesar da década de 1970 representar a abertura da temática e, por consequência, receber as obras mais "clássicas", apenas uma publicação dessa década figura entre as de maior impacto: Property rules, liability rules, and environmental economics, de D. W. Bromley e que foi publicada no Journal of economic issues em 1978. Três autores possuem mais de uma publicação de destaque: Robert S. Pindyck (Uncertainty in Environmental Economics e Optimal timing problems in environmental economics, de, respectivamente, 2007 e 2002), Jeroen C. J. M. van den Bergh (Evolutionary thinking in environmental economics e Ecological economics: themes, approaches, and differences with environmental economics s de, respectivamente, 2007 e 2001) e Olof Johansson-Stenman (Fair Air: Distributive Justice and Environmental Economics e The importance of ethics in environmental economics with a focus on existence values, de, respectivamente, 2010 e 1998). Nenhuma revista publicou mais que duas obras de impacto sobre Economia Ambiental.

Realizada a análise avaliativa, passou-se para a análise relacional dos pesquisadores e publicações que compõem o campo da Economia Ambiental. Com a utilização do programa VOSviewer version 1.6.12 foi possível elaborar mapas bibliométricos que ilustram de que maneira a temática em estudo tem se organizado desde seu início. O primeiro ponto abordado, apresentado na Figura 7, a seguir, é sobre a produção amparada em coautoria.

Figura 7 - Rede de coautoria, por autores.

\section{vosviewer}

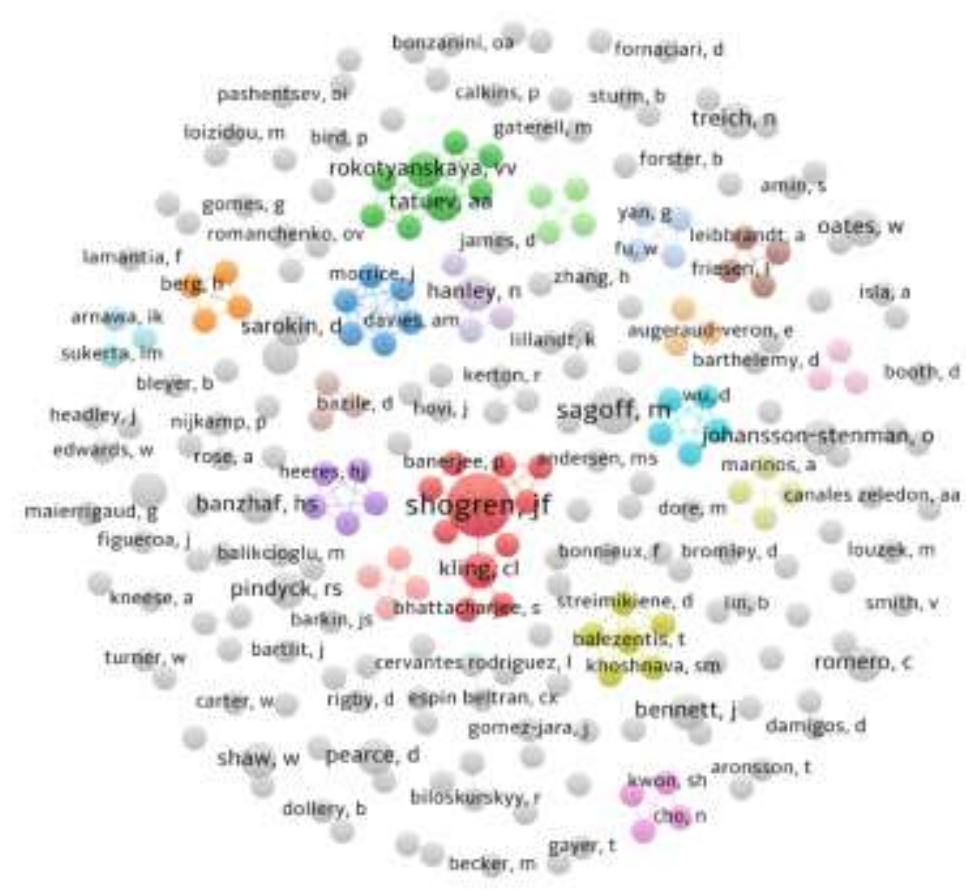

Fonte: Elaborado pelos autores (2020).

Analisando o mapa de coautoria, observa-se bastante dispersão entre os autores participantes do campo. Objetivamente, apesar de se configurar como uma temática com 250 autores pesquisadores, existem apenas dois clusters de pesquisa que concretamente integram autores com publicações distintas. O mais significativo desses conglomerados está destacado em 
vermelho na figura e é composto por 11 autores. Destes, o autor mais produtivo é J. F. Shogren, com 5 obras publicadas e que ocupa papel central no cluster. O segundo conglomerado, em verde na figura, é formado por 8 autores, tendo V. V. RokoTyanskaya e A. A. Tatuev como pesquisadores com mais publicações (2). O fato de terem se formado uma quantidade tão pequena de clusters e de tamanho tão reduzido indica pouca colaboração entre grupos de pesquisa, o que, certamente, implica em desenvolvimento pouco acelerado do campo em estudo. Cabe destacar que apenas 18 autores publicaram mais de uma vez sobre a temática. Talvez exista pouca continuidade no desenvolvimento das pesquisas, visto que é pouco provável que tenha ocorrido um esgotamento do assunto. Por outro lado, existe a possibilidade do campo de estudo ser tão vasto e complexo que a rede formada ainda é historicamente muito jovem e, com o passar do tempo, as novas pesquisas e publicações integrarão grupos já existentes de pesquisa e resultarão em novos e maiores clusters de cooperação. Prosseguindo na análise, a Figura 8 , a seguir, apresenta a rede bibliométrica de coautoria por organizações.

Figura 8 - Rede de coautoria, por organizações.

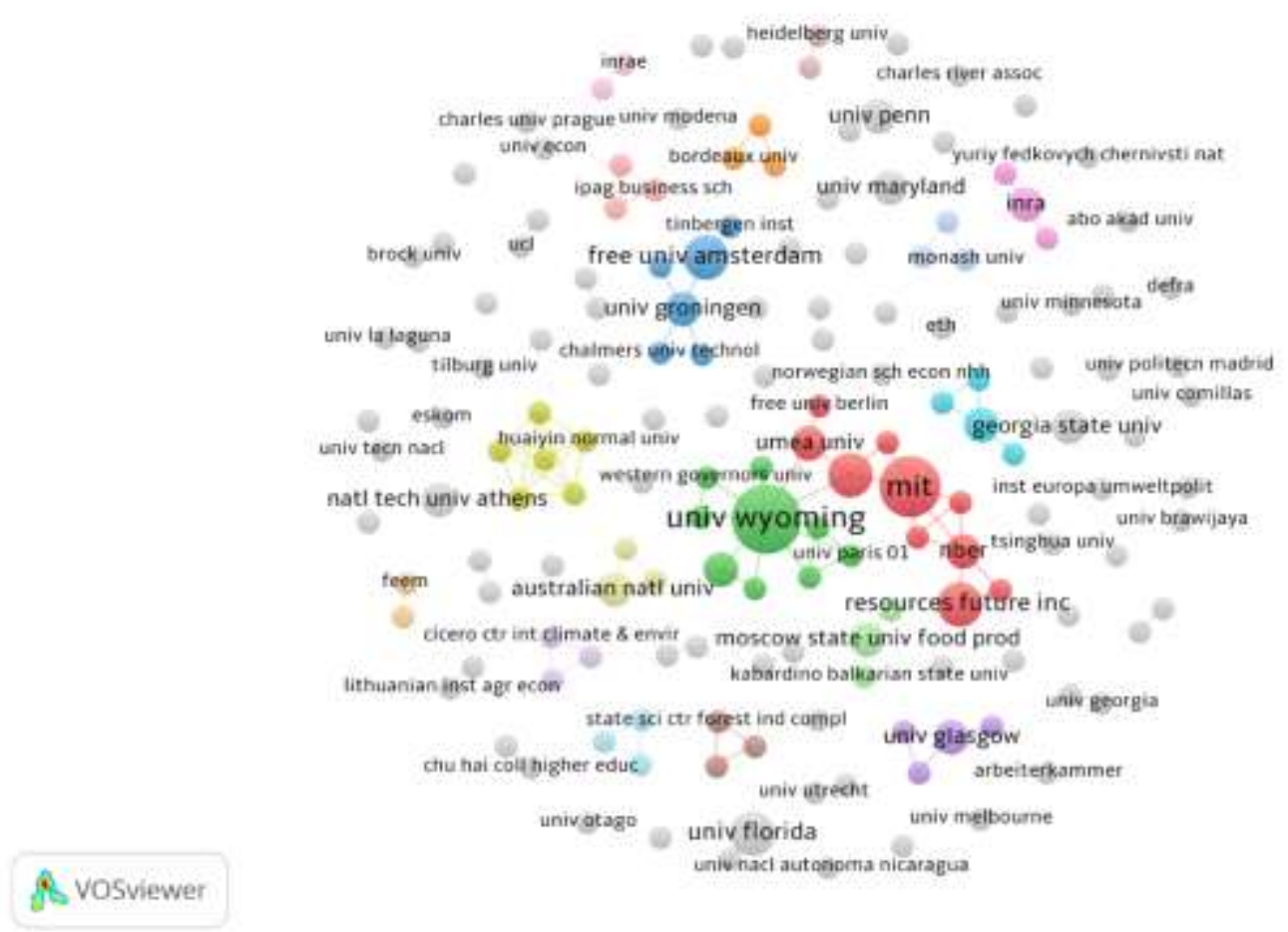

Fonte: Elaborado pelos autores (2020).

Em relação ao mapa de coautoria por autores, aqui observamos a formação de uma quantidade maior de conglomerados de cooperação. O mais destacado de todos é o cluster em vermelho no mapa. Este é formado por 10 organizações. O Massachusetts Institute of Tecnology (MIT) ocupa papel central nesse conglomerado, tendo realizado 5 publicações. Também compõem o grupo as instituições Harvard University, North Carolina State University, Georgetown University e outras organizações americanas - configurando um núcleo de pesquisa estadunidense. O segundo conglomerado de destaque é o cluster assinalado em verde na figura. A University of Wyoming é a mais destacada com 6 publicações sobre a temática em estudo. Todavia, existe nesse cluster participação de instituições europeias, como o GREQAM CNRS, Paris School of Economics e a University British Columbia, indicando uma integração maior de abordagens entre escolas estadunidense e europeia. O terceiro cluster de destaque na rede (em azul na figura) é composto por 6 organizações e tem como expoente a Free University Amsterdam (com 3 publicações). Esse conglomerado é majoritariamente europeu - com exceção da University of Southern California. Os 
demais clusters formados são de menor expressão, com produtividade incipiente, ou repetem o que já foi reconhecido na análise por coautoria de pesquisadores, em que a sub-rede está embasada apenas em uma publicação conjunta. A partir dessas observações, a sequencia natural de análise é interpretar a rede de coautoria por países, apresentada, a seguir na Figura 9.

Figura 9 - Rede de coautoria, por países.

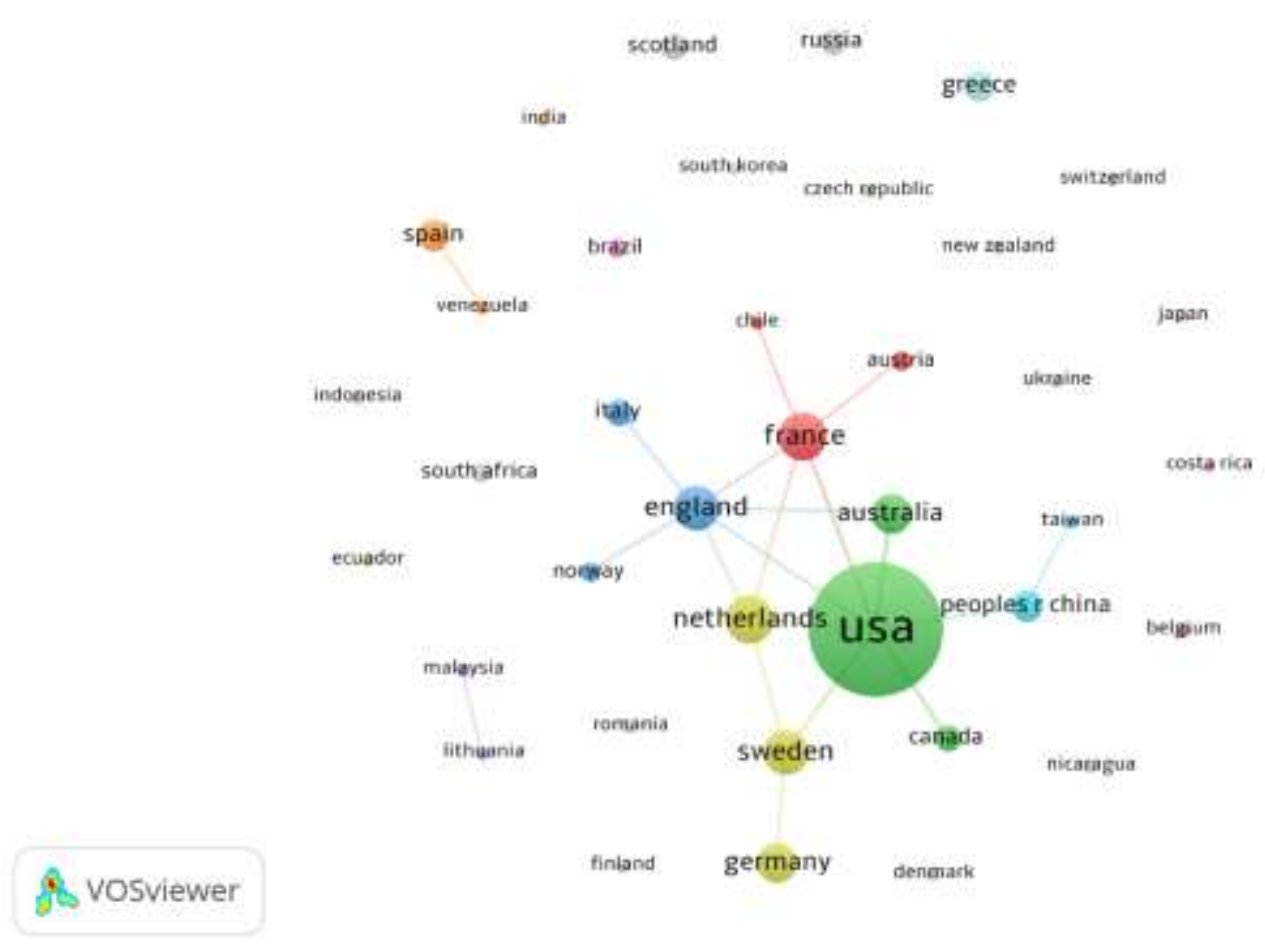

Fonte: Elaborado pelos autores (2020).

Conforme mencionado anteriormente, 38 países possuem pesquisadores que publicaram sobre Economia Ambiental. Uma análise inicial permite constatar que boa parte destes não está inserido em nenhum cluster de colaboração sobre o tema (inclusive o Brasil). Cabe reforçar que a formatação de clusters se dá pela relação de frequência de cooperação entre os itens da rede. Dessa maneira, aparecem na rede 4 conglomerados de cooperação destacados, cada um composto por 3 países. Em verde, observa-se o cluster formado por EUA, Austrália e Canadá. Obviamente, em função de sua quantidade de publicações, que EUA assumem papel de destaque no cluster. O segundo é formado por França, Áustria e Chile. Neste, a França se apresenta como a mais produtiva com 8 publicações. Em azul, tem-se o cluster integralmente europeu, formado por Inglaterra, Itália e Noruega. A Inglaterra possui 7 publicações nesse grupo. Por fim, e caracterizando outro cluster essencialmente europeu, aparece (em amarelo) Holanda, Suécia e Alemanha - neste a Holanda se mostra mais produtiva com 7 publicações. De forma geral, temos aqui um reforço do que foi observado na análise da figura 6, ou seja, em termos continentais, existe grande presença de países europeus pesquisando sobre a dinâmica do tema apresentado. Apesar de todas as constatações realizadas, a complementação da análise necessita abordar de que maneira o campo de estudo está se desenvolvendo em termos de assuntos ou quais formações de subcampos estão se delineando. Isso pode ser realizado a partir da interpretação da rede bibliométrica de coocorrência de termos, apresentada na Figura 10, a seguir. 
Figura 10 - Rede de coocorrência de termos.

\section{Vosviewer}

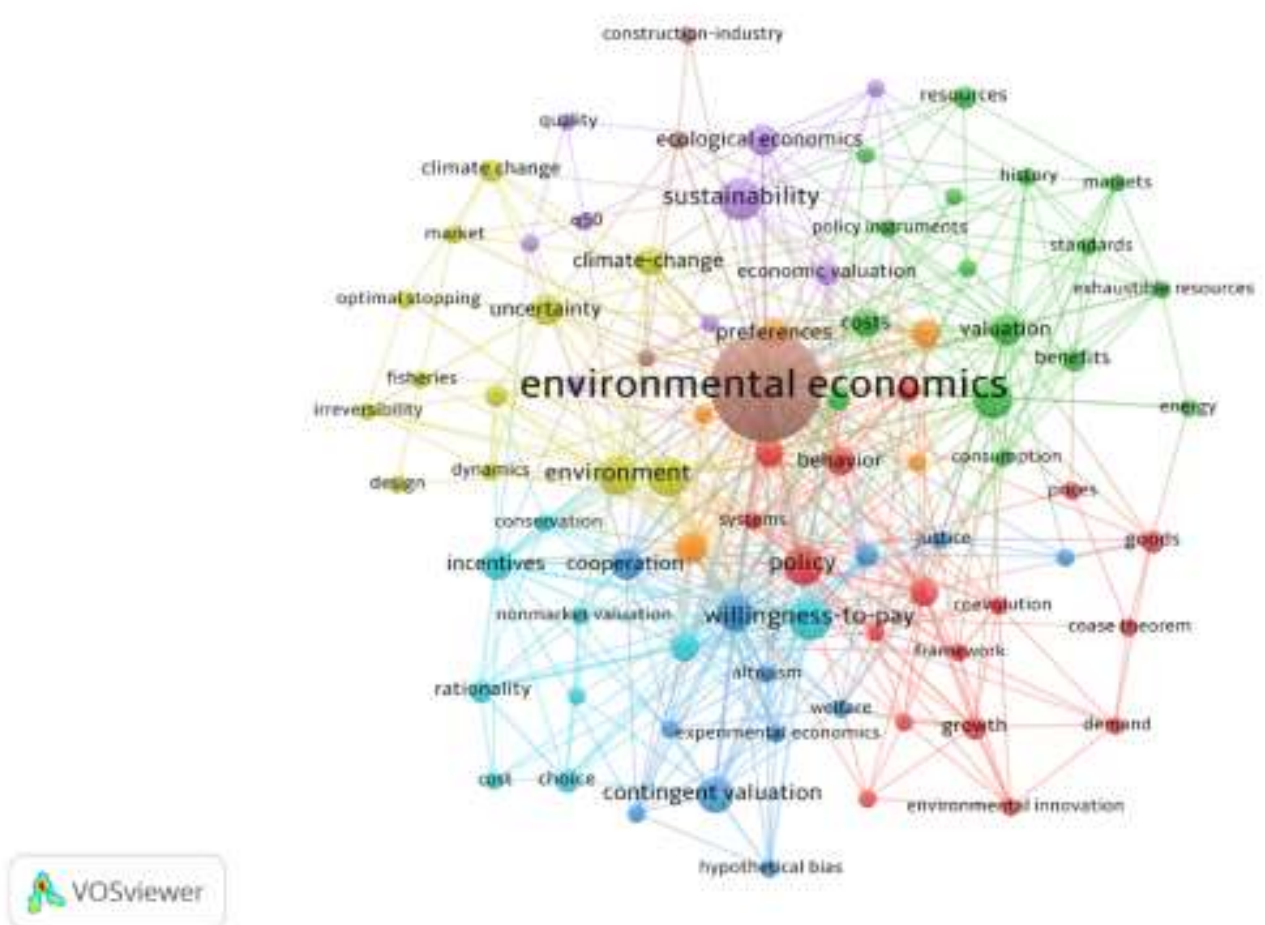

Fonte: Elaborado pelos autores (2020).

Obviamente que "Economia Ambiental" se encontra fortemente relacionada a boa parte (maioria) dos assuntos abordados nas publicações investigadas. Isso se dá pela própria natureza da pesquisa que condicionou à busca das publicações à existência desse tema. Observado isso, é possível constatar a existência de 8 clusters de assuntos na rede, o que deve indicar o delineamento de subcampos de estudo dentro da temática geral. O primeiro cluster destacado, (em vermelho no mapa), com 17 itens, tem como termo com mais associações o tema "poluição". Estão, na rede, fortemente vinculados a essa temática os termos "política", "modelo", “comportamento", "progresso" e "crescimento". Percebemos aqui um subcampo ocupado em discutir causas e efeitos da poluição, assim como busca de soluções para a problemática. O segundo cluster de destaque (em verde no mapa), possui 16 itens e tem como temas de destaque o "desenvolvimento sustentável" e "avaliação". Aparecem fortemente associados os termos "custos", "benefícios", "instrumentos", "consumo" e "eficiência". Vemos aqui um núcleo de pesquisa que procura discutir abordagens sobre o pensamento acerca de desenvolvimento sustentável, considerando reconhecidamente associadas, como consumo, custos e eficiência. O terceiro cluster a se destacar (em azul no mapa), com 12 itens, tem como assunto marcante os "bens comuns". Nesse grupo, se encontram fortemente associados a esse tema a cooperação, o método “contingent valuation”, a economia experimental, o altruísmo e a ética. Percebe-se nesse subcampo, um esforço para discutir, inclusive no âmbito conceitual, quais os valores estão associados ao bem comum, relacionando essa temática a aspectos de natureza coletiva, como a cooperação, ética e altruísmo. Por fim, o último cluster a destacar (em amarelo no mapa), é composto por 12 itens e tem como tema central "política ambiental". Estão fortemente relacionados os assuntos "mudança climática", “incerteza", “ambiente" e "informação". Nesse conglomerado, claramente, se procura dialogar sobre as problemáticas que impactam a delimitação eficiente de políticas ambientais, recebendo destaque aspectos que adicionam complexidade ao tema, como a incerteza, mudanças climáticas e a quantidade e qualidade de informações. De maneira geral, o campo da Economia Ambiental parece estar composto por subcampos com temáticas bem delimitadas, apesar da evidente integração quase que total entre os assuntos que compõem a rede. 


\section{Conclusão}

O objetivo central deste estudo foi analisar a produção científica internacional sobre Economia Ambiental, utilizando como base a plataforma Web of Science. Como resultado, foi possível constatar uma tendência crescente de publicações sobre o tema, assim como de busca e citações das obras que compõem essa temática. Conclui-se que os EUA é o principal promotor de pesquisas, embora um volume expressivo de países europeus faça parte da composição geral de nações pesquisadoras. Também foram identificadas as obras de maior impacto, de acordo com o H-Index: um total de 27 publicações, sendo a de maior destaque Environmental economics - a survey, escrita por M. L. Cropper e W. E. Oates e que foi publicada em 1992 no Journal of economic literature.

Já em termos relacionais, utilizou-se o software VOSviewer version 1.6.12 para formatar redes bibliométricas que permitissem uma interpretação visual sobre conglomerados de cooperação e associação em torno da temática. Constatou-se pouca clusterização em termos de coautoria e pesquisa, o que indicou pouca integração entre grupos, organizações e países. Com relação aos subcampos dentro da temática, observou-se a formação de 4 clusters destacados, cujos temas centrais foram poluição, desenvolvimento sustentável, bens comuns e política ambiental.

De forma geral, percebe-se que a temática Economia Ambiental se encontra em franco desenvolvimento, com crescimento de interesse e com delineamento claro de subcampos que indicam o direcionamento para novas pesquisas, assim como os gaps para fortalecimento do tema.

\section{Referências}

Andersen, Mikael Skou. An introductory note on the environmental economics of the circular economy. Sustainability Science, v. 2, n. 1, p. $133-140,2007$. doi:10.1007/s11625-006-0013-6.

Berg, H.; Ohman, M. C.; Troeng, S.; Linden, O. Environmental economics of coral reef destruction in Sri Lanka. AMBIO, v. 27, n. 8, p. 627-634, 1998.

Bromley, Daniel W. Property Rules, Liability Rules, and Environmental Economics. Journal of Economic Issues, v. 12, n. 1, p. 43-60, 1978. doi:10.1080/00213624.1978.11503504.

Cropper, M. L.; Oates, W. E. Environmental economics - a survey. Journal of economic literature, v. 30, p. 675-740, 1992.

Croson, Rachel; Treich, Nicolas. Behavioral Environmental Economics: Promises and Challenges. Environmental and Resource Economics, v. 58, n. 3, p. 335-351, 2014. doi:10.1007/s10640-014-9783-y.

Faber, Albert; Freken, Koen. Models in evolutionary economics and environmental policy: Towards an evolutionary environmental economics. Technological Forecasting and Social Change, v. 76, n. 4, p. 462-470, 2009. doi:10.1016/j.techfore.2008.04.009.

Fisher, Anthony C. Investment under uncertainty and option value in environmental economics. Resource and Energy Economics, v. 22, n. 3, p. 197-204, 2000. doi:10.1016/S0928-7655(00)00025-7.

Gil, Antônio Carlos. Métodos e técnicas de pesquisa social. 6. ed. São Paulo: Atlas, 2008.

GREENSTONE, Michael; GAYER, Ted. Quasi-experimental and experimental approaches to environmental economics. Journal of Environmental Economics and Management, v. 57, n. 1, p. 21-44, 2009. doi:10.1016/j.jeem.2008.02.004.

Hanley, Nick; RYAN, Mandy; WRIGHT, Robert. Estimating the monetary value of health care: lessons from environmental economics. Health economics, v. 12, n. 1, p. 3-16, 2003. doi:10.1002/hec.763.

Hirsch, J. E. An index to quantify an individuals scientific research output. Proceedings of the National Academy of Sciences of the United States of America, v.102, n.46, p.16569-16572, 2005. doi: https://doi.org/10.1073/pnas.0507655102

JOHANSSON-STENMAN, Olof. The importance of ethics in environmental economics with a focus on existence values. Environmental and Resource Economics, v. 11, 3/4, p. 429-442, 1998. doi:10.1023/A:1008239427421.

JOHANSSON-STENMAN, Olof; KONOW, James. Fair Air: Distributive Justice and Environmental Economics. Environmental and Resource Economics, v. 46, n. 2, p. 147-166, 2010. doi:10.1007/s10640-010-9356-7.

Koseoglu, M. A. Growth and structure of authorship and co-authorship network in the strategic management realm: Evidence from the Strategic Management Journal. Business Research Quarterly, v.19, p.153-170, 2016. doi: https://doi.org/10.1016/j.brq.2016.02.001 
Research, Society and Development, v. 10, n. 3, e15510312450, 2021

(CC BY 4.0) | ISSN 2525-3409 | DOI: http://dx.doi.org/10.33448/rsd-v10i3.12450

Linares, P. Aggregation of preferences in an environmental economics context: a goal-programming approach. Omega, v. 30, n. 2, p. 89-95, 2002. doi:10.1016/S0305-0483(01)00059-7.

Munda, Giuseppe. Environmental Economics, Ecological Economics, and the Concept of Sustainable Development. Environmental Values, v. 6, n. 2, p. 213233, 1997. doi:10.3197/096327197776679158.

Norgaard, Richard B. Environmental economics: An evolutionary critique and a plea for pluralism. Journal of Environmental Economics and Management, v. 12, n. 4, p. 382-394, 1985. doi:10.1016/0095-0696(85)90007-5.

Pearce, David. An Intellectual History of Environmental Economics. Annual Review of Energy and the Environment, v. 27, n. 1, p. 57-81, 2002.

doi:10.1146/annurev.energy.27.122001.083429.

Pindyck, Robert S. Optimal timing problems in environmental economics. Journal of Economic Dynamics and Control, v. 26, 9-10, p. 1677-1697, 2002. doi:10.1016/S0165-1889(01)00090-2.

Pindyck, Robert S. Uncertainty in Environmental Economics. Review of Environmental Economics and Policy, v. 1, n. 1, p. 45-65, 2007. doi:10.1093/reep/rem002.

Quigin, John. Environmental economics and the Murray-Darling river system. Australian Journal of Agricultural and Resource Economics, v. 45, n. 1, p. 6794, 2001. doi:10.1111/1467-8489.00134.

Sagoff, Mark. Some Problems with Environmental Economics. Environmental Ethics, v. 10, n. 1, p. 55-74, 1988. doi:10.5840/enviroethics198810128.

Shogren, Jason F.; TAYLOR, Laura O. On Behavioral-Environmental Economics. Review of Environmental Economics and Policy, v. 2, n. 1, p. 26-44, 2008. doi:10.1093/reep/rem027.

Soolner, Fritz. A reexamination of the role of thermodynamics for environmental economics. Ecological Economics, v. 22 , n. 3, p. $175-201,1997$. doi:10.1016/S0921-8009(97)00078-5.

Sturm, Bodo; WEIMANN, Joachim. Experiments in Environmental Economics and Some Close Relatives. Journal of Economic Surveys, v. 20, n. 3, p. 419457, 2006. doi:10.1111/j.0950-0804.2006.00285.x.

Swaney, James A. Elements of a Neoinstitutional Environmental Economics. Journal of Economic Issues, v. 21, n. 4, p. $1739-1779,1987$. doi:10.1080/00213624.1987.11504721.

Van de Bergh, Jeroen C. J. M. Ecological economics: themes, approaches, and differences with environmental economics. Regional Environmental Change, v. 2, n. 1, p. 13-23, 2001. doi:10.1007/s101130000020.

Van de Bergh, Jeroen C. J. M. Evolutionary thinking in environmental economics. Journal of Evolutionary Economics, v. 17, n. 5, p. 521-549, 2007. doi:10.1007/s00191-006-0054-0.

Van Eck, N. J.; Waltman, L. Citation-based clustering of publications using CitNetExplorer and VOSviewer. Scientometrics, v.111, p.1053-1070, 2017. doi: https://doi.org/10.1007/s11192-017-2300-7

VENKATACHALAM, L. Environmental economics and ecological economics: Where they can converge? Ecological Economics, v. 61, 2-3, p. 550-558, 2007. doi:10.1016/j.ecolecon.2006.05.012.

Welsh, Heinz. Implications of happiness research for environmental economics. Ecological Economics, v. 68, n. 11, p. 2735-2742, 2009.

doi:10.1016/j.ecolecon.2009.06.003. 